\title{
Danielle Birkett and Dominic McHugh, eds., Adapting the Wizard of Oz: Musical Versions from Baum to MGM and Beyond
}

New York: Oxford University Press, 2019 [272 pp. ISBN: $9780190663186 . \$ 35.00$ (paperback)]. Photographs, music examples, illustrations, tables, appendix, and index.

\section{MEGAN WOLLER}

Gannon University

woller001@gannon.edu

A daptation has always been an intrinsic part of American musical theater and film. As such, scholars of musicals have long acknowledged the role of adapting familiar works for new audiences. In recent years, however, more intensive research has been done on this time-honored practice. ${ }^{1}$ In Adapting the Wizard of Oz: Musical Versions from Baum to MGM and Beyond, Danielle Birkett and Dominic McHugh have put together a primer for studying adaptation in musicals from a number of perspectives. The Wizard of $\mathrm{Oz}$ is among the most treasured adapted properties of the twentieth century. Thus, a volume exploring the musical versions of Frank L. Baum's renowned children's fantasy offers a compelling case for a study of this kind.

McHugh and Birkett bring together a number of scholars to look at many aspects of The Wizard of $\mathrm{Oz}$ in its musical incarnations from a variety of perspectives. Unsurprisingly, the majority of the twelve contributors are musicologists and, appropriately, scholars whose research centers on musical theater and film music. Indeed, several of the contributors have previously published work addressing different facets of The Wizard of $\mathrm{Oz}$, or on related topics. ${ }^{2}$ At the same time,

1 In fact, Dominic McHugh also edited The Oxford Handbook of Musical Theatre Screen Adaptations (New York, Oxford University Press, 2019).

2 See Ryan Bunch, "Oz and the Musical: The American Art Form and the Reinvention of the American Fairy Tale," Studies in Musical Theatre 9, no. 1 (2015): 53-69; Walter Frisch, Arlen and Harburg's Over the Rainbow (New York: Oxford University Press, 2017); and Paul Laird, The Musical Theater of Stephen Schwartz: From Godspell to Wicked and Beyond (Lanham, MD: Rowman \& Littlefield, 2014).
Claudia Funder's discussion, which centers on dance, represents the diversity of analytical approaches. Taken together, the collection offers a fascinating look at a well-known and beloved story from a multitude of perspectives written by experts in their various research areas.

After an introduction in which Birkett and McHugh consider the importance of The Wizard of $\mathrm{Oz}$, the edited volume begins with an essay investigating an early adaptation by Jonas Westover. The author delivers a fascinating look at a noweclipsed stage adaptation of Baum's The Wizard of $\mathrm{Oz}$, and successfully highlights the interplay between adaptation, star performances, and Baum's extension of the Oz stories. Baum's own involvement in the early stage adaptation as well as the production's success actually influencing the creation of subsequent $\mathrm{Oz}$ stories reveals the potential depth of the relationship between adaptations and their source material. Although the 1939 MGM film has surpassed the cultural importance of the early twentieth century stage musical, this essay shows that the cultural resonance of the story as a musical adaptation has long and important roots.

Given the prominence of MGM's stunning 1939 film, it is no surprise that the majority of this edited collection explores the film and its cultural import from a variety of angles. Since each of the essays is self-contained, some overlap necessarily-yet sometimes repetitively-occurs. On the whole, 
however, this section provides a rich look at The Wizard of $\mathrm{Oz}$, revealing the multifaceted nature of adaptation studies in relation to this single film musical. Collectively, the next chapters illustrate the intricacies of adaptation as a topic and reveal how much there is to be done in this area.

Benjamin Sears writes the first chapter to focus on the 1939 film specifically. He analyzes the process of adapting the novel into the film as well as the conceptual similarities and differences between the two. Sears's essay tracks no less than ten writers working on the screenplay, including lyricist E.Y. Harburg. Readers come to understand the highly complicated process of working on the final screenplay as well as how shaping that screenplay ultimately affected interpretation of the story.

While Sears reveals the significant role Harburg played in developing the final script, Laura Lynn Broadhurst explores the issue of creative control with regard to the film's songs. Broadhurst complicates the idea of authorship in light of Hollywood practices and, particularly, the songwriting process as it applies to The Wizard of $\mathrm{Oz}$. She maps the creative process of songwriting across all of the production stages, from Harburg and Arlen's initial songwriting to audience reception and interpretation. Broadhurst uses archival research and interviews to explore the role of arrangers, orchestrators, the imprint of the vocalists, and other personnel responsible for the final product. Once again, both process and product are given equal weight, demonstrating the complexity of adaptation as a concept.

Nathan Platte's essay posits that the orchestral scoring acts as a type of special effect, noting the importance of "attractions" and the special effect in Baum's own style as well as the MGM film. Platte deftly uses three case studies in order to investigate the role of the underscoring in The Wizard of $\mathrm{Oz}$; the music for the cyclone sequence, the use of disembodied voices, and the musical depiction of magical characters all serve to underline Platte's point.

Shifting from music to dance, Claudia Funder discusses the film's choreographic approach. She notes that the 1939 finished film actually includes a relatively small amount of dancing. Yet her detailed discussion of the stage design for Munchkinland as well as the surprising complexity of Dorothy's skip foregrounds the role of dance as well as Funder's contention that dance enhances the cultural impact of the film. Additionally, Funder's discussion of the two cut dance scenes, "The Jitterbug" and the Scarecrow's extended dance, gives the reader a taste of what the film could have been.

The next two chapters deal with various aspects of the reception history of The Wizard of $\mathrm{Oz}$. Co-editor Danielle Birkett considers the immediate reception and accumulated popular and critical success of the 1939 film. Drawing on an array of reviews, Birkett usefully contextualizes the initial reception of the film based on preconceived notions and oft-made comparisons not only to Baum but Disney. She teases out the role of television in raising the film to its iconic status, thus cementing its legacy. In the next chapter, Hannah Robbins explores queer cultural associations with the film and attaches these cultural meanings to an effective queer reading of the film itself. As Robbins notes, there are "few more recognizable works so intrinsically associated with popular American queer culture" (p. 143). Robbins then details the reasons for this connection, looking at Judy Garland's status as a gay icon and the myriad potential meanings of the coded "friends of Dorothy" designation, among other signifiers.

Dominic McHugh, also a co-editor, transitions into the final essays which deal with the influence and lasting effects of MGM's version of The Wizard of $\mathrm{Oz}$. McHugh introduces the reader to three stage musical adaptations of the film. The intertextuality and layering present in adaptive works looms large in this essay. The author considers the 1942 St. Louis Municipal Theater production, the Royal Shakespeare Company's version, and Andrew Lloyd Webber's more recent adaptation. McHugh's essay highlights the differing approaches to fidelity in terms of the plot and score as well as considerations regarding star performances and the possibilities of the stage versus film.

In the next chapter, Ryan Bunch shifts to a discussion of The Wiz. He explores how the musical uses "soul music to make a black commentary on a white text" (p. 186). Bunch discusses how soul music represents black experience. He considers the social impact and reception of both the original stage production and film before moving on to provide his own reading regarding how The Wiz characterizes a history of black migratory experience and the importance of self-discovery as a theme. The resulting essay offers the reader convincing insight into the cultural significance of the musical.

Dovetailing with his previous work on Wicked, Paul Laird considers the intertextual nature of the musical. Laird sets up the levels of adaptation at play by first considering Gregory Maguire's 1995 novel. 
He then notes composer Stephen Schwartz's desire to make explicit references to the MGM film, which resulted in legal wrangling on the part of Universal. Throughout his essay, Laird manages to convey the complexity of references without getting bogged down in a potentially confusing comparison. Wicked emerges as a rich adaptation, not only of Maguire's novel but of the MGM film, with the ability to color audience's experience of the earlier film. Most notably, Laird states that Wicked "complicated our understanding of the Wicked Witch of the West" (p. 220).

In the final essay of the collection, Walter Frisch leaves us with a taste of the cultural resonance of The Wizard of $\mathrm{Oz}$ through its songs. He gives a quick rundown of some significant recordings of the film's songs since 1939 and their varied meanings. Understandably, much of Frisch's chapter deals with 'Over the Rainbow' due to its exalted status. He asserts that this song "has transcended its original context far more widely and frequently than other numbers in the film" (p. 229). From its continued associated with Judy Garland throughout her life and career to jazz recordings and IZ's successful single,
Frisch shows how 'Rainbow' has entered into the fabric of American popular culture.

With a variety of approaches represented throughout the volume, Birkett and McHugh's edited volume offers a valuable contribution to the study of musical adaptations. Additionally, the consistent accessibility of the collection and focus on a beloved film and related works makes this appealing for enthusiasts of the genre and The Wizard of $\mathrm{Oz}$. By no means comprehensive, Adapting the Wizard of $\mathrm{Oz}$ leaves room for additional research on this fascinating and well-loved work.

Megan Woller is an Assistant Professor of Fine Arts at Gannon University. Her research interests include film music, musical theater, popular music, and music and gender. She has presented her work at conferences such as Society for American Music and Popular Culture Association/American Culture Association. Dr. Woller's articles on film and musical adaptations appear in Studies in Musical Theatre, Music and the Moving Image, the Journal of Popular Culture, and The Oxford Handbook of Screen Adaptations. 